\title{
Global SUMOylation is a molecular mechanism underlying hypothermia-induced ischemic tolerance
}

\author{
Yang-ja Lee ${ }^{\dagger}$, Yongshan Mou ${ }^{\dagger}$, Dace Klimanis, Joshua D. Bernstock and John M. Hallenbeck*
}

Stroke Branch, National Institute of Neurological Disorders and Stroke, National Institutes of Health, Bethesda, MD, USA

Edited by:

Dirk M. Hermann, University

Hospital Essen, Germany

Reviewed by:

Catarina Oliveira, University of

Coimbra, Portugal

Sasidhar Reddy Murikinati, Yale

University School of Medicine, USA

*Correspondence:

John M. Hallenbeck, Stroke Branch,

National Institute of Neurological

Disorders and Stroke, National

Institutes of Health,

Bldg10/Rm5B02, MSC 1401,

10 Center Drive, Bethesda

MD 20892, USA

e-mail: hallenbj@ninds.nih.gov

${ }^{\dagger}$ These authors have contributed

equally to this work.
The molecular mechanisms underlying hypothermic neuroprotection have yet to be fully elucidated. Herein we demonstrate that global SUMOylation, a form of posttranslational modification with the Small Ubiquitin-like MOdifer, participates in the multimodal molecular induction of hypothermia-induced ischemic tolerance. Mild $\left(32^{\circ} \mathrm{C}\right)$ to moderate $\left(28^{\circ} \mathrm{C}\right)$ hypothermic treatment(s) during OGD (oxygen-glucose-deprivation) or ROG (restoration of oxygen/glucose) increased global SUMO-conjugation levels and protected cells (both SHSY5Y and E18 rat cortical neurons) from OGD and ROGinduced cell death. Hypothermic exposure either before or after permanent middle cerebral artery occlusion (pMCAO) surgery in wild type mice increased global SUMOconjugation levels in the brain and in so doing protected these animals from pMCAOinduced ischemic damage. Of note, hypothermic exposure did not provide an additional increase in protection from pMCAO-induced ischemic brain damage in Ubc9 transgenic (Ubc9 Tg) mice, which overexpress the sole E2 SUMO conjugating enzyme and thereby display elevated basal levels of global SUMOylation under normothermic conditions. Such evidence suggests that increases in global SUMOylation are critical and may account for a substantial part of the observed increase in cellular tolerance to brain ischemia caused via hypothermia.

Keywords: Hypothermia, SUMOylation, pMCAO, Neuroprotection, Ubc9

\section{INTRODUCTION}

Stroke is the fourth leading cause of death and a leading cause of long-term disability in adults (Roger et al., 2012). While a myriad of cellular and molecular brain injury mechanisms have been reported in preclinical stroke models (reviewed in Dirnagl et al., 1999; Mergenthaler et al., 2004; Broussalis et al., 2012a), the individual targeting of these mechanisms has thus far not proven effective (reviewed in O'Collins et al., 2006, 2009; Broussalis et al., 2012b). In the wake of such failures ischemic brain damage has gradually become viewed as a highly complex, multifactorial process that involves the interplay of many non-dominant effectors (Hallenbeck and Frerichs, 1993; Hallenbeck, 2002; Iadecola and Anrather, 2011).

In contrast to the aforementioned failures, hypothermia has been recognized as perhaps the most robust brain cytoprotectant studied in the laboratory to date (reviewed in González-Ibarra et al., 2011; Yenari and Han, 2012). The neuroprotective effects conferred by hypothermia are multifactorial. As such, hypothermia has been shown to alter a number of the pathologic molecular mechanisms induced by cerebral ischemia. Such changes include

Abbreviations: SUMO, small ubiquitin-related modifier; OGD, oxygenglucose deprivation; ROG, recovery from oxygen/glucose deprivation; Ubc9, ubiquitin conjugase 9; Tg, transgenic; pMCAO, permanent middle cerebral artery occlusion. reductions in metabolic and enzymatic activity, glutamate release and re-uptake, inflammation, the production of reactive oxygen species, and expression of various genes (reviewed in GonzálezIbarra et al., 2011; Yenari and Han, 2012). Preliminary clinical studies utilizing mild to moderate hypothermia as a treatment for acute ischemic stroke are ongoing and results obtained thus far have been encouraging (Macleod et al., 2010; van der Worp et al., 2010; Abdullah and Husin, 2011; Kollmar et al., 2012). Despite such work and the reproducible demonstrations of hypothermic neuroprotection by a number of laboratories, the cellular and molecular mechanisms underlying brain cytoprotection induced via exposure to hypothermia are not fully understood.

One candidate capable of coordinating the multimodal molecular mechanisms that underlie the cytoprotection induced in the brain as a consequence of cooling is that of global SUMOylation. Post-translational modification by this ubiquitinlike modifier (ULM) appears to have multifunctional effects and operates in states of tolerance to preserve homeostasis under stress (Tempé et al., 2008). We have previously reported on the massive increases in SUMOylation that occur in 13-lined ground squirrels during hibernation torpor, a period in which their body temperature declines to $5^{\circ} \mathrm{C}$ (deep hypothermic condition) (Lee et al., 2007). We hypothesized such massive increases in SUMOconjugation were involved in the profound natural tolerance to the reductions in brain blood flow and oxygen delivery displayed by these hibernating animals. Our work and that of others have 
shown that global SUMOylation is indeed involved in ischemic tolerance in both in vitro cell culture systems (Lee et al., 2007, 2009; Datwyler et al., 2011; Cimarosti et al., 2012) and animal models (Cimarosti et al., 2008; Yang et al., 2008; Lee et al., 2011).

SUMO, like ubiquitin, is synthesized as an inactive precursor and subsequently processed by SUMO-specific proteases to yield the mature di-glycine C-terminus. A single heterodimeric E1 activating enzyme (SAE1/SAE2) initiates conjugation by adenylating SUMO. This is followed by the formation of a covalent thioester E1-SUMO intermediate. SUMO is then transferred to the catalytic cysteine of the sole E2 conjugase, Ubc9 (Ubiquitin conjugase 9), which alone or in concert with an E3 ligase catalyzes the formation of an isopeptide linkage between the C-terminal glycine residue of SUMO and the epsilon-amino group of the substrate's lysine residue. The conjugation actions of Ubc9 are opposed by isopeptidases, which catalyze deSUMOylation thereby modulating steady state levels of SUMOconjugates (reviewed in Müller et al., 2001; Hay, 2005). There are three systemically distributed SUMO paralogs in mammals: the sequences of SUMO-2 and SUMO-3 are 96\% identical and are therefore difficult to distinguish. In contrast, SUMO-1 is only $45 \%$ identical with to the other two SUMO paralogs and has a distinct immunoreactivity (Tatham et al., 2001).

Of note, we have generated Ubc9 transgenic (Ubc9 Tg) mice, which displayed increased levels of SUMO-conjugation and an improved tolerance to permanent middle cerebral artery occlusion (pMCAO)-induced brain damage (Lee et al., 2011). Using these Ubc9 Tg mice, the human neuroblastoma cell line SHSY5Y and E18 derived rat cortical neurons, we present evidence that strongly links hypothermia-induced ischemic resilience to corresponding levels of global SUMOylation.

\section{MATERIALS AND METHODS SHSY5Y CELL CULTURE AND ISOLATION OF RAT CORTICAL NEURONS/CULTURE}

The human neuroblastoma cell line SHSY5Y (American Type Culture Collection, Manassas, VA, USA) was cultured in Dulbecco's modified Eagle's medium (DMEM) supplemented with $10 \%$ heat-inactivated fetal bovine serum, $100 \mathrm{U} / \mathrm{ml}$ penicillin, and $100 \mathrm{mg} / \mathrm{ml}$ streptomycin (DMEM complete) in $5 \% \mathrm{CO}_{2}$ at $37^{\circ} \mathrm{C}$. Embryos (day 18) of Sprague-Dawley rats were used to prepare cortical neuronal cultures. Cortices were dissected from the embryos, dissociated with papain (Worthington Biochemicals, Lakewood, NJ, USA), and plated out at 1,000,000 cells per well on poly-L-lysine-coated 6 well plates in Neurobasal-A/B27 media (Lee et al., 2009). Cells were used after 7 days in culture.

\section{OXYGEN AND GLUCOSE DEPRIVATION (OGD), RESTORATION OF OXYGEN-GLUCOSE (ROG), HYPOTHERMIA, AND THE ASSESSMENT OF CELL DEATH}

Oxygen-glucose-deprivation (OGD) using SHSY5Y cells and cortical neuronal cultures was performed as previously described (Lee et al., 2007, 2009). OGD was carried out either at $37^{\circ} \mathrm{C}$ (normothermia) or $32^{\circ} \mathrm{C}$ (hypothermia). After a $12 \mathrm{~h}$ (SHSY5Y) or 3-9 h (cortical neurons) incubation, plates were taken out of the OGD chamber, OGD media was replaced with complete media which contained glucose (DMEM for SHSY5Y and Neurobasal-A/B27 for cortical neurons), and incubated for an additional $16 \mathrm{~h}$ at $37^{\circ} \mathrm{C}$ (normothermia), $32^{\circ} \mathrm{C}$ or $28^{\circ} \mathrm{C}$ (hypothermia) for restoration of oxygen/glucose (ROG).

Cell death as induced by OGD alone or after ROG was assessed by nuclear staining with Hoechst 33342 and propidium iodide via fluorescence-activated cell sorting (FACS) analysis as described previously (Lee et al., 2007), or followed by counting directly under the fluorescent microscope (Lee et al., 2009).

\section{ANIMAL EXPERIMENTS}

The National Institute of Neurological Disorders and Stroke Animal Care and Use Committee approved all experiments under the protocol \#1268-12 entitled "Use of Ubc9 Tg mice for preclinical study of stroke." Ubc9 Tg mice were generated as previously described (Lee et al., 2011). An equal number of male and female adult mice (18-20 weeks old, weighing between 20-30 g) were used throughout the course of all experiments. Of note, within this aged cohort males typically weighed more than females, but brain sizes amongst males and females were comparable and no significant gender differences in susceptibility to pMCAO-induced brain damage were noted in the course of our studies. Animal hypothermia was induced by using the water immersion method described previously (Mou et al., 2013). Using this method, body temperature was tightly controlled and we noted that brain temperature (BT) was consistently recorded to be $0.3-0.5^{\circ} \mathrm{C}$ higher than the rectal temperature recorded during hypothermic treatment. We therefore used rectal temperature as a surrogate capable of monitoring BT. Animals were eliminated from the study if any of the follow conditions were met: (i) hemorrhage from the MCA; (ii) injury to another branch of MCA; (iii) extreme cerebral blood flow change (i.e., $<70 \%$ and $>90 \%$ ); and (iv) inconsistent body temperature control (surgery $<36.5^{\circ} \mathrm{C}$ and $>37.5^{\circ} \mathrm{C}$ ) + (hypothermia $<0.2^{\circ} \mathrm{C}$ and $>0.2^{\circ} \mathrm{C}$ of intended target temperature). The animals used in these experiments were randomized and the surgeon was blinded as to the genetic backgrounds of the animals. The evaluation of infarct size was conducted in manner that blinded one to both the experimental conditions and animal's genetic background.

Oxygen saturation, heart and respiratory rates were monitored using an Oximeter (STARR Life Sciences Corporation). Focal cerebral ischemia was induced via $\mathrm{pMCAO}$ in mice as previously described (Lee et al., 2011). Briefly, a $1.5 \sim 2.0 \mathrm{~cm}$ incision was made between the left eye and ear. A craniectomy was then performed at the skull base ( $\sim 2 \mathrm{~mm}$ in diameter) to expose, cauterize and transect the left MCA and it's anterior branch (if available) at the level of the olfactory tract. Of note, $24 \mathrm{~h}$ of a focal pMCAO procedure will normally cause an infarct that occupies about onethird of the ipsilateral hemisphere. As such, at $24 \mathrm{~h}$ after surgery (unless otherwise described), each animal was anesthetized with isoflurane and decapitated. Brains were promptly removed and snap frozen for the assessment of brain damage and for Western blot analysis of global SUMO-conjugation.

\section{WESTERN BLOT ANALYSIS}

The lysates from SHSY5Y cells or cortical neurons (Lee et al., 2007, 2009) and brain extracts (Lee et al., 2007, 2011) 
were prepared as previously described. Rabbit polyclonal antiSUMO-1 and anti-SUMO-2/3 antibodies (both developed inhouse) and anti- $\beta$-actin antibody (Sigma Chemical) were used. The intensities of bands were analyzed using Image-J (NIH). In order to measure SUMO-conjugation levels, the region corresponding to molecular weights $65 \sim 300 \mathrm{kDa}$ for cells and $\sim 90$ to $250 \mathrm{kDa}$ for mouse brains in each lane were cropped and the total intensity was analyzed (Lee et al., 2007).

\section{Cresyl VIOLET STAINING AND THE ASSESSMENT OF INFARCTION VOLUMES}

Frozen brain coronal sections $(20 \mu \mathrm{m})$ from both WT and Ubc9 Tg mice, which had undergone $24 \mathrm{~h}$ of pMCAO were stained with cresyl violet; brain damage was subsequently assessed as previously described (Lee et al., 2011). Briefly, quantification of the infarct area was performed on $20 \mu \mathrm{m}$ cresyl-violet-stained sections collected at $0.34 \mathrm{~mm}$ intervals. The infarct area of each section was measured using Image J. The effect of edema was corrected for using the following equation (Leach et al., 1993): corrected infarct area $=$ infarct area $\times$ area of contralateral hemisphere / area of ipsilateral hemisphere. Infarct volume $\left(\mathrm{mm}^{3}\right)$ was calculated for each animal by integrating the corrected infarct area with the distance between sections $(0.34 \mathrm{~mm})$ (Arsenijevic et al., 2006).

\section{STATISTICS}

Variables were analyzed (two group comparison) using a MannWhitney $\mathrm{U}$ test with a Bonferroni correction. $p<0.05$ was considered statistically significant. All values are expressed as a mean \pm SD (standard deviation) of at least three independent experiments with at least 6 animals contained within each group. Correlations between two variables of interest were obtained using Spearman's correlation coefficient. $p<0.05$ was considered to be statistically significant.

\section{RESULTS}

\section{HYPOTHERMIA EXPOSURE INCREASES GLOBAL SUMO-CONJUGATION LEVELS AND PROTECTS SHSY5Y CELLS AND RAT CORTICAL NEURONS FROM OGD-INDUCED CELL DEATH}

We examined whether mild $\left(32^{\circ} \mathrm{C}\right)$ to moderate $\left(28^{\circ} \mathrm{C}\right)$ hypothermia, both of which fall within the temperature range used to induce clinical hypothermia, would be capable of increasing SUMO-conjugation levels, and if so, would such an increase be beneficial in an effort to protect cells from ischemic damage. We first examined SHSY5Y cells for SUMO-1 conjugation levels during $\mathrm{OGD}$, or $\mathrm{OGD} / \mathrm{ROG}$ at $37^{\circ} \mathrm{C}, 32^{\circ} \mathrm{C}$, or $28^{\circ} \mathrm{C}$. As shown in Figure 1A, $12 \mathrm{~h} \mathrm{OGD}$ at $37^{\circ} \mathrm{C}$ decreased SUMO-1 conjugation (40\% decrease from control), yet the decrease was much smaller (less than 20\%) when cells were subjected to OGD at $32^{\circ} \mathrm{C}$. Of note, the levels of global SUMO-conjugation did not change further when ROG was carried out at $37^{\circ} \mathrm{C}$, but the conjugation levels significantly increased when ROG was carried out at either $32^{\circ} \mathrm{C}$ or $28^{\circ} \mathrm{C}$. These results clearly indicate that hypothermic treatments can both preserve during OGD and increase during ROG the levels of SUMO-1 conjugation in SHSY5Y cells. As shown in Figure 1B, $12 \mathrm{~h}$ of OGD at $37^{\circ} \mathrm{C}$ resulted in $\sim 60 \%$

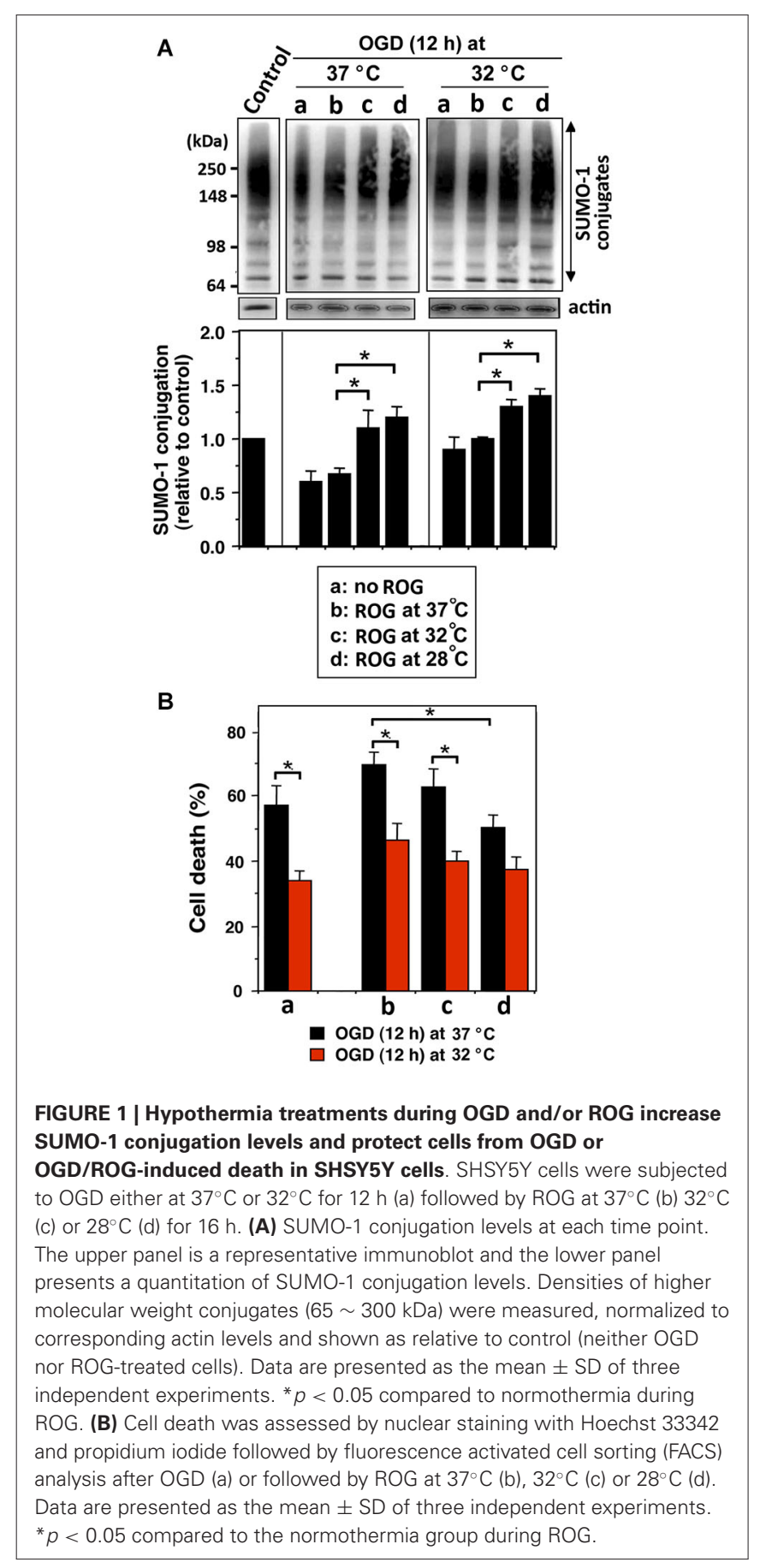

cell death, but the same length of $\mathrm{OGD}$ at $32^{\circ} \mathrm{C}$ reduced cell death to a mere $\sim 35 \%$. Further, cell death induced by OGD at $37^{\circ} \mathrm{C}$ continue to increase following ROG at $37^{\circ} \mathrm{C}$ to $70 \%$, but was significantly reduced (to $\sim 50 \%$ ) when ROG was carried out at $28^{\circ} \mathrm{C}$. As such, in line with previously published reports hypothermic treatment inhibits cell death caused by either OGD alone or OGD/ROG in SHSY5Y cells. Next, we carried out a similar set of experiments utilizing primary cultures of E18 rat cortical neurons. We examined the effects of hypothermic treatment on both global SUMO-1 conjugation levels and cell death during 


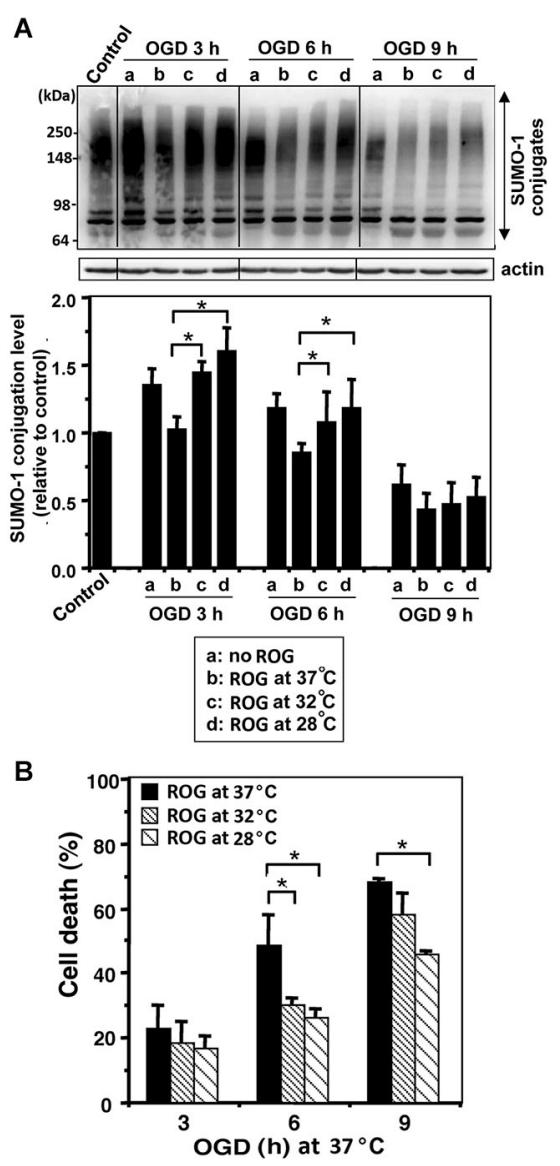

FIGURE 2 | Hypothermic treatments during ROG increase SUMO-1 conjugation levels and protect cells from OGD/ROG-induced death in rat cortical neurons. Rat cortical neuronal cultures were subjected to OGD at $37^{\circ} \mathrm{C}$ for 3,6 or $9 \mathrm{~h}$ followed by ROG at $37^{\circ} \mathrm{C}$ (b) $32^{\circ} \mathrm{C}$ (c) or $28^{\circ} \mathrm{C}$ (d) for $16 \mathrm{~h}$. (A) SUMO-1 conjugation levels at each time point: control, OGD alone (a) and OGD/ROG (b: $37^{\circ} \mathrm{C}, \mathrm{c}: 32^{\circ} \mathrm{C}, \mathrm{d}: 28^{\circ} \mathrm{C}$ ). Representative immunoblots (upper panel) and quantitation of SUMO-1 conjugation levels (lower panel). Densities of high molecular weight conjugates $(65 \sim 300 \mathrm{kDa})$ were measured, normalized to corresponding actin levels and shown as relative to controls that did not receive an OGD or ROG exposure. Data are presented as the mean \pm SD of three independent experiments. (B) Cell death was assessed by nuclear staining with Hoechst 33342 and propidium iodide followed by counting directly under the fluorescent microscope ( $\geq 300$ cells) after $O G D$ at $37^{\circ} \mathrm{C}$ and $R O G$ at $37^{\circ} \mathrm{C}, 32^{\circ} \mathrm{C}$, or $28^{\circ} \mathrm{C}$. Data are presented as the mean $\pm \mathrm{SD}$ of three independent experiments. ${ }^{*} p<0.05$ compared to normothermic OGD group.

ROG. Primary cortical neurons were subjected to OGD at $37^{\circ} \mathrm{C}$ for 3,6 , or $9 \mathrm{~h}$, followed by ROG at $37^{\circ} \mathrm{C}, 32^{\circ} \mathrm{C}$, or $28^{\circ} \mathrm{C}$. As shown in Figure 2A, short durations of OGD increased SUMO-1 conjugation (i.e., preconditioning), but conjugation was drastically decreased by longer/more lethal OGD. Of note, the SUMO-1 conjugation that was increased by shorter periods of OGD gradually decreased during ROG at $37^{\circ} \mathrm{C}$. However, SUMO-1 conjugation levels in these cells were restored and/or increased when ROG was carried out under hypothermic conditions $\left(32^{\circ} \mathrm{C}\right.$ or $\left.28^{\circ} \mathrm{C}\right)$. In our experimental setting, $3 \mathrm{~h}$ of OGD followed by $16 \mathrm{~h}$ of ROG resulted in a modest amount of cell death in cortical neurons, and thus the protective effects of hypothermia were minimal (Figure 2B). $6 \mathrm{~h}$ of OGD followed by $16 \mathrm{~h}$ ROG at $37^{\circ} \mathrm{C}$ caused over $50 \%$ cell death in cortical neuronal cells, but hypothermia treatment during ROG was capable of significantly decreasing cell death (Figure 2B). 9 h of OGD was very severe for the cortical neurons, yet hypothermic treatment during ROG (especially at $28^{\circ} \mathrm{C}$ ) was capable of inducing significant protection (Figure 2B).

\section{WT MICE EXPOSED TO HYPOTHERMIA BEFORE PMCAO SURGERY SHOWED ELEVATED SUMO-CONJUGATION LEVELS IN THE BRAIN AND WERE PROTECTED FROM pMCAO-INDUCED BRAIN DAMAGE, WHILE Ubc9 Tg MICE DISPLAYED NO ADDITIONAL PROTECTION AFTER HYPOTHERMIC TREATMENT}

We followed the hypothermic preconditioning paradigm that was initially used in rats (Yunoki et al., 2003) for our mouse experiments. In so doing, we compared WT mice with mice that were transgenic for Ubc9, the sole E2 SUMO conjugase. The hypothermic treatment paradigm employed is diagrammed in Figure 3A: BT of WT and Ubc9 Tg animals was cooled to $28^{\circ} \mathrm{C}$ over a period of $20 \mathrm{~min}$, maintained at $28^{\circ} \mathrm{C}$ for $20 \mathrm{~min}$, then increased to $37^{\circ} \mathrm{C}$ over a period of $20 \mathrm{~min}$, and finally maintained at $37^{\circ} \mathrm{C}$ for 20 min before the pMCAO surgery. The $\mathrm{BT}$ of the normothermia group was kept at $37^{\circ} \mathrm{C}$ for $80 \mathrm{~min}$ under anesthesia before the pMCAO surgery. SUMOylation levels throughout the entire brain were analyzed at each time point during the hypothermic treatment. As shown in Figures 3B,C, SUMO- 1 and SUMO-2/3 conjugation levels in the brain were increased when BT was maintained at $28^{\circ} \mathrm{C}$ (stages $2-3$ ). Of note some of the increases persisted even when the BT was returned to $37^{\circ} \mathrm{C}$ (stage 4) in WT animals. The Ubc9 Tg mice demonstrated trends similar to WT, yet the overall conjugation levels were predominantly higher than WT. Interestingly, SUMO-1 (and SUMO-2/3) conjugation levels at stage 4, just before pMCAO surgery, were essentially identical for WT and Ubc9Tg mice. When hypothermia-pretreated WT mice were subjected to pMCAO for $24 \mathrm{~h}$, brain damage (infarction volume) was significantly less ( $\sim 50 \%$ reduction) as compared to normothermic WT animals (Figure 3D). As reported in our previous paper (Lee et al., 2011), Ubc9 Tg mice were more resistant to pMCAO even under normothermic condition, and no further reduction in brain damage was achieved via hypothermic treatment (Figure 3D).

\section{HYPOTHERMIC TREATMENT OF WT MICE AFTER PMCAO-SURGERY ELEVATED SUMO-CONJUGATION LEVELS IN THE BRAIN AND DECREASED pMCA0-INDUCED BRAIN DAMAGE, WHILE Ubc9 Tg MICE THAT RECEIVED THE SAME TREATMENT PARADIGM DISPLAYED NO FURTHER PROTECTION}

In order to examine the effects of hypothermia on the pathologic outcomes induced by the pMCAO surgery, animals (WT and Ubc9 $\mathrm{Tg}$ ) were subjected to surgery first after which their BTs were maintained either at $37^{\circ} \mathrm{C}, 32^{\circ} \mathrm{C}$ or $28^{\circ} \mathrm{C}$ for $2 \mathrm{~h}$. Twenty four hours later brains were harvested and ischemic damage assessed. The treatment paradigm we employed is diagrammed in Figure 4A. First, we examined the SUMO conjugation levels in WT and Ubc9Tg brains at each time point (1-5). As shown 


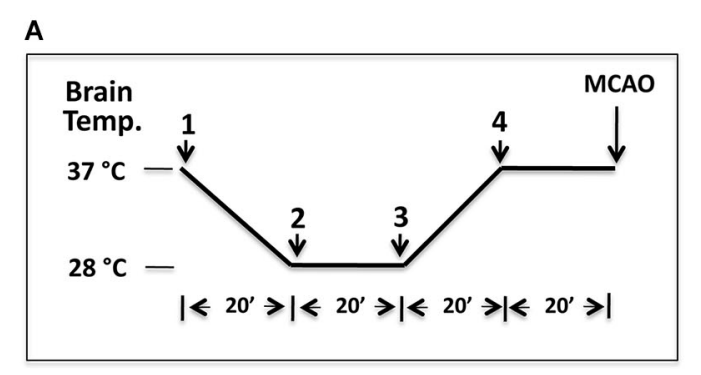

B

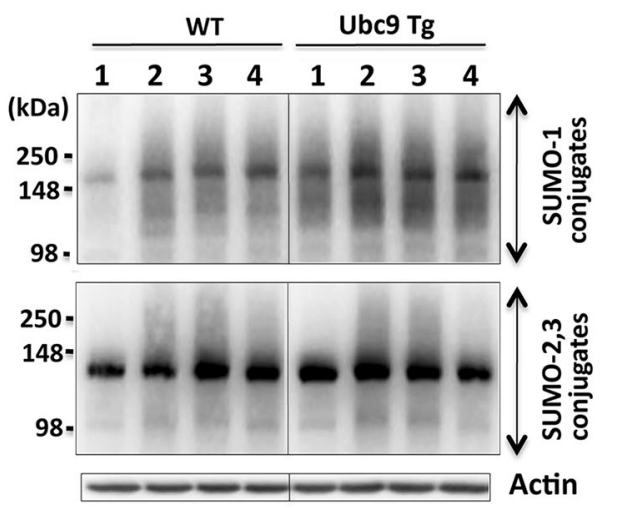

C
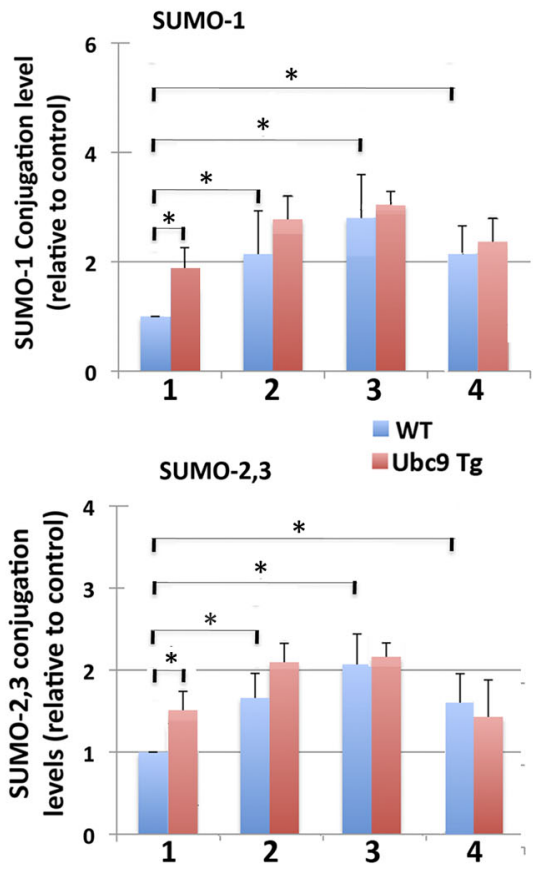

D

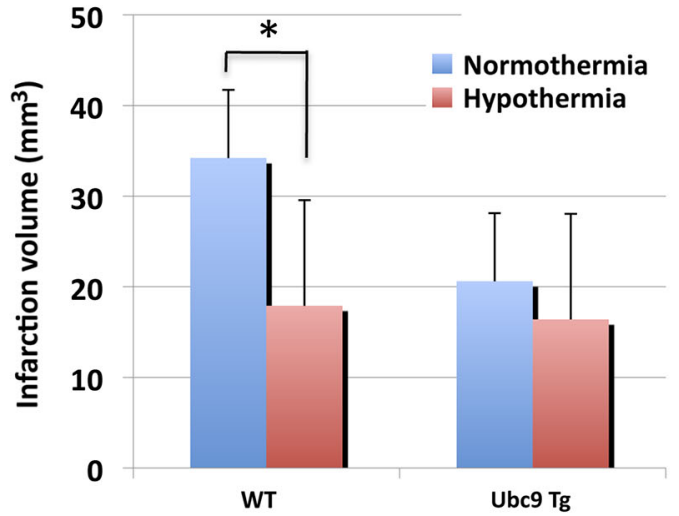

FIGURE 3 | Effects of hypothermia exposure before pMCAO surgery on brain SUMOylation levels and on subsequent PMCAO-induced ischemic brain injury. (A) Diagram of serial temperature stages used during hypothermic exposure of mice. Animals (WT and Ubc9 Tg) (1) were cooled to $28^{\circ} \mathrm{C}$ (BT) over a period of $20 \mathrm{~min}(2)$, maintained at a BT of $28^{\circ} \mathrm{C}$ for $20 \mathrm{~min}(3), \mathrm{BT}$ was increased to $37^{\circ} \mathrm{C}$ over a period of $20 \mathrm{~min}$ (4), and $\mathrm{BT}$ was maintained at $37^{\circ} \mathrm{C}$ for $20 \mathrm{~min}$ before $\mathrm{pMCAO}$ surgery. (B) Representative immunoblots for SUMO-1 conjugation (upper panel) and SUMO-2/3 conjugation (lower panel) in whole brain extracts. At time/temperature points $1-4$, animals were euthanized and brains were promptly removed and frozen for the Western blot analysis of SUMO conjugation. Whole brain extracts were prepared and equal amounts of protein $(20 \mu \mathrm{g})$ were analyzed for SUMO conjugation. Actin levels were also examined in the same blot. (C) Quantitative analyses of SUMO-1 conjugation (upper panel) and SUMO-2/3 conjugation (lower panel) at each time point. Densities of higher molecular weight conjugates $(90 \sim$ $250 \mathrm{kDa}$ ) were measured, normalized to the corresponding actin level and shown relative to control (WT, without hypothermia). Blue: WT, and Red: Ubc9Tg mice. Data are presented as the mean \pm SD of 6 animals per group (WT and Ubc9Tg) at each time point. (D) Hypothermia exposure before PMCAO surgery significantly reduces $\mathrm{pMCAO-induced} \mathrm{infarction}$ volume in WT mice, but not in Ubc9 Tg mice. WT and Ubc9 Tg mice that had been exposed to hypothermia and their normothermic control animals in which brain temperatures had been maintained at $37^{\circ} \mathrm{C}$ under anesthesia for the same total duration as the hypothermia experimental groups $(80 \mathrm{~min})$ were subjected to $\mathrm{pMCAO}$, and $24 \mathrm{~h}$ later the brain infarction volumes were measured. Blue: normothermia, Red: hypothermia. Data are presented as the mean \pm SD of 6 WT and 6 Ubc9 Tg animals in each of the two conditions (normothermia and hypothermia). ${ }^{*} p<0.05$ compared to normothermia. in Figures 4B,C, SUMO-conjugation levels (both SUMO-1 and SUMO-2/3) in WT mice were significantly lower than those in Ubc9Tg mice prior to pMCAO (stage 1, normothermia). SUMO-2/3 conjugation, but not SUMO-1 conjugation in WT mice, was increased by the pMCAO surgery (stage 2). SUMO-1 and SUMO-2/3 conjugation levels were slightly decreased or unchanged during the recovery stage at $37^{\circ} \mathrm{C}$ (stage 3 ) in WT mice. Critically, when BTs were kept at either $32^{\circ} \mathrm{C}$ (stage 4 ) or 

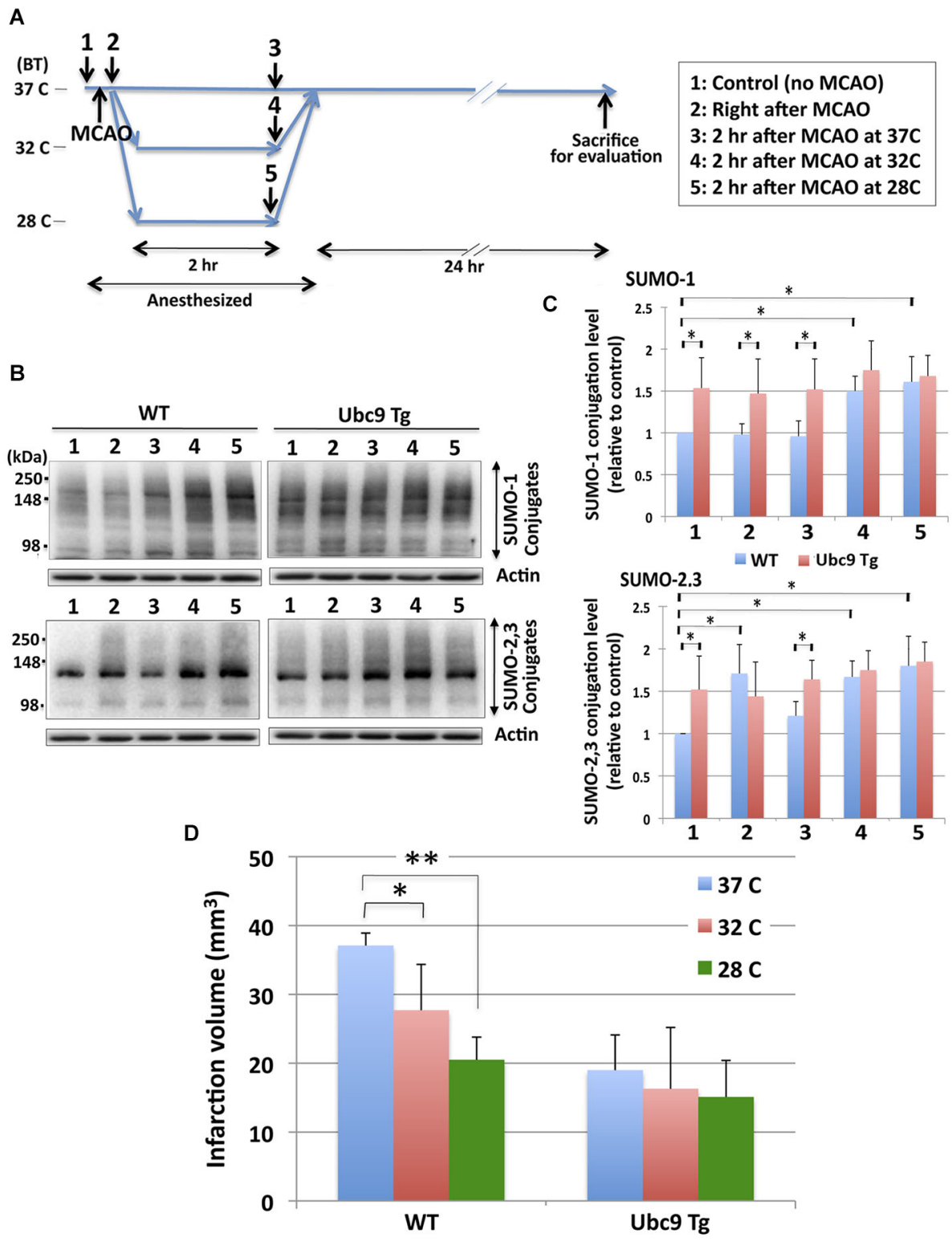

FIGURE 4 | Effects of hypothermia exposure after pMCAO surgery on brain SUMOylation levels and PMCAO-induced brain injury.

(A) Diagram of hypothermia treatment protocol used in the mice. Animals (WT and Ubc9 Tg) (1) were subjected to pMCAO surgery (2). After surgery one group of WT and Ubc9 Tg animals had BTs maintained at $37^{\circ} \mathrm{C}$ for $2 \mathrm{~h}$ (3) another group at $32^{\circ} \mathrm{C}$ for $2 \mathrm{~h}(4)$, and a third group at $28^{\circ} \mathrm{C}$ for $2 \mathrm{~h}(5)$ under anesthesia. All animals recovered from anesthesia and were housed at room temperature with BTs equal to $\sim 37^{\circ} \mathrm{C}$ for $24 \mathrm{~h}$ before evaluating brain damage. (B) Representative immunoblots for SUMO-1 (upper panel) and SUMO-2/3 (lower panel) conjugation in the whole brain extracts from WT and Ubc9 Tg mice. At each time point (1-5), 6 animals in each group were euthanized, brains were promptly removed and frozen for Western blot analysis. Whole brain extracts were prepared and equal amounts of protein $(20 \mu \mathrm{g})$ were analyzed for SUMO conjugation. Actin levels were also examined in the same blot as loading controls.

(C) Quantitation of SUMO-1 (upper panel) and SUMO-2/3 (lower panel) conjugation levels at each time point in WT and Ubc9 Tg. Densities of higher molecular weight conjugates $(90 \sim 250 \mathrm{kDa})$ were measured, normalized with corresponding actin levels and shown relative to controls (WT with no pMCAO). Blue: WT, and Red: Ubc9 Tg. Data are presented as the mean \pm SD of 6 animals from the WT and from the Ubc9 Tg groups at each time point. (D) Hypothermia exposure after pMCAO surgery significantly reduces pMCAO-induced infarction volume in WT mice, but not in Ubc9 Tg mice. Animals (WT and Ubc9 Tg) (18 animals from each group) that had received pMCAO surgery were divided into 3 temperature groups each with 6 WT and 6 Ubc9 Tg: one temperature group's BTs were maintained at $37^{\circ} \mathrm{C}$ for $2 \mathrm{~h}$; another at $32^{\circ} \mathrm{C}$ for $2 \mathrm{~h}$; and another at $28^{\circ} \mathrm{C}$ for $2 \mathrm{~h}$ under anesthesia. All animals recovered from anesthesia and were housed at room temperature for $24 \mathrm{~h}$ and evaluated for brain infarct volumes. Blue: $37^{\circ} \mathrm{C}$, red: $32^{\circ} \mathrm{C}$, green: $28^{\circ} \mathrm{C}$. Data are presented as the mean \pm SD of six of each animals (WT and Ubc9 Tg) group in each condition. ${ }^{*} p<0.05 ;{ }^{*} p<0.01$. $28^{\circ} \mathrm{C}$ (stage 5) after pMCAO surgery, SUMO conjugation levels in WT mice were increased (stage $3 \ll$ stage $4<$ stage 5 ). SUMO conjugation levels in Ubc9 $\mathrm{Tg}$ were generally higher than WT (except SUMO-2/3 at stage 2) and were essentially unchanged by 
hypothermic treatment. Of note, under hypothermia, especially at $28^{\circ} \mathrm{C}$, SUMOylation levels in both the WT and Ubc9 $\mathrm{Tg}$ mice were effectively identical (Figures 4B,C). Next, we examined the effect of hypothermia after pMCAO surgery on ischemic brain damage. As shown in Figure 4D, hypothermic treatment (particularly at $28^{\circ} \mathrm{C}$ ) for $2 \mathrm{~h}$ after the surgery significantly reduced brain damage in WT mice after pMCAO. In accordance with our previous work Ubc9 $\mathrm{Tg}$ mice displayed much less ischemic brain damage in the normothermic group, yet no gains in protection were evident in the hypothermic groups (Figure 4D). We did notice that brain infarction volumes in the $32^{\circ} \mathrm{C}$ treated animal groups (both WT and Ubc9 Tg) varied greatly. As such, we analyzed the correlation of infarction volumes and SUMOylation levels among these animals (6 WT, 6 Ubc9 Tg), and found that infarction volumes did display a significant inverse linear correlation with that of SUMO-1 conjugation levels (Spearman $=-0.60839, P=0.0358)$, and an inverse linear correlation trend for SUMO-2/3 conjugation levels (Spearman $=-0.56643$, $P=0.0548$ ). These results provide evidence that hypothermia exposure increases tolerance to brain ischemia in a manner that is in direct proportion to its capacity to increase in global SUMOylation.

\section{DISCUSSION}

The cytoprotective effects induced via elevated levels of SUMOconjugation have been reported in cell lines (Lee et al., 2007, 2009), primary neuronal cultures (Lee et al., 2009; Datwyler et al., 2011; Cimarosti et al., 2012) and in the brains of both rats (Cimarosti et al., 2008; Yang et al., 2008) and mice (Lee et al., 2011). Increases in SUMOylation via hypothermic treatments have been identified in hibernating ground squirrels (Lee et al., 2007), and were further noted in cell lines (Lee et al., 2007), primary neuronal cultures (Loftus et al., 2009; Wang et al., 2012) and rats (Yang et al., 2009; Wang et al., 2012). Herein, we have shown that global SUMOylation is increased and sustained by both mild and moderate hypothermia during OGD and ROG in both SHSY5Y cells (Figure 1A) and rat cortical neurons (Figure 2A). It is prudent to note that in those cells in which SUMOylation was augmented by hypothermia, a concordant increase in tolerance to OGD and OGD/ROG-induced cell death was exhibited (Figures 1B, 2B). It is therefore reasonable to deduce from both our work and that of others that global SUMOylation may be one of the molecular mechanisms underlying hypothermia-induced ischemic neuroprotection.

To further explore this putative mechanism we used transgenic animals whose phenotype involves constitutively elevated levels of global SUMOylation. Our Ubc9 Tg mice have been previously phenotyped and the neuroprotection (post-focal brain ischemia) afforded via the upregulation of SUMOylation in these animals characterized (Lee et al., 2011). A myriad of different experimental animal models for therapeutic hypothermia have been reported (reviewed in Krieger and Yenari, 2004; Nagel et al., 2008): each of which utilizes different depths, durations, and times of onset for hypothermia. Further, different animals and models of stroke induction have been employed (Evdokimov et al., 2008; Zhang et al., 2008). We performed two sets of experiments: one using hypothermia as a preconditioning stress (i.e., hypothermic treatment before an ischemic challenge), and the other using hypothermia as a post-conditioning stress (i.e., as a therapeutic intervention after an ischemic challenge). In so doing, we followed the hypothermic preconditioning paradigm put forth by K.S. Lee's group (Nishio et al., 2000; Yunoki et al., 2002, 2003) for our mouse experiments. By keeping the BT of WT mice at $28^{\circ} \mathrm{C}$ for 20 min before a pMCAO challenge (Figure 3A), SUMOylation levels in the brain were shown to be increased (Figures 3B,C) while brain damage was reduced significantly (Figure 3D). Ubc9 $\mathrm{Tg}$ mice display baseline global SUMOylation levels higher than those of WT and as such displayed a greater tolerance to pMCAOinduced ischemic brain damage in the normothermic state than WT mice (Lee et al., 2011). However, the Ubc9 Tg mice exhibited no additional benefits from hypothermic preconditioning (Figure 3D) which was in stark contrast to the WT mice. When used in the post-occlusion period, hypothermia also showed significant protection from $\mathrm{pMCAO}$-induced brain damage in WT animals, but not in Ubc9 Tg mice (Figure 4). Again, it is prudent to note that both experimental paradigms could only increase tolerance to brain ischemia if that exposure resulted in a corresponding increase in global SUMOylation. These results strongly suggest that global SUMOylation is an important mechanism in the induction of ischemic tolerance via exposure to hypothermia.

Throughout the course of this study our Ubc9 $\mathrm{Tg}$ mice demonstrated no additional gain in ischemic cytoprotection from hypothermic treatment, which was in direct contrast to what we witnessed in our WT controls. If SUMOylation is indeed a critical component of the myriad of protective molecular responses induced by hypothermia, Ubc9 $\mathrm{Tg}$ mice (which have constitutively elevated levels of global SUMOylation even under normothermic conditions) would be expected to fail in displaying an increase in brain cytoprotection resultant from hypothermic exposure to the same degree as WT mice. This outcome is in line with our results and provides a direct link between levels of SUMOylation and the litany of protective molecular mechanisms underlying hypothermia-induced cytoprotection post-ischemia. Unfortunately, SUMO-1,2,3 knock-out animals are not yet available with which to investigate whether SUMO-conjugation is an underlying molecular mechanism in hypothermia-induce ischemic tolerance through a series of loss of function experiments. While SUMO-1 knock-out mice have been reported, the majority of SUMO-1 functions were compensated for in vivo by SUMO-2 and SUMO-3 (Evdokimov et al., 2008; Zhang et al., 2008). Similarly, when all three SUMO isoforms are prevented from functioning via the overexpression of a dominant negative Ubc9 mutant or by knocking Ubc9 down in vitro cells are not capable of surviving (Hayashi et al., 2002; Nacerddine et al., 2005; Lee et al., 2007).

Among the many experimental stroke therapies hypothermia remains one of the most effective and promising neuroprotectants studied to date. However, several obstacles continue to impede its clinical translation. As such, pharmacologically induced hypothermia has been proposed as a very attractive alternative 
(Katz et al., 2004; Yenari et al., 2008; Choi et al., 2012). If one considers that global SUMOylation may in fact be one of the critical underlying mechanisms of hypothermia-induced cytoprotection, the clinical utility in seeking ways to induce an increase in global SUMOylation pharmacologically becomes readily apparent. Accordingly, we are in the process of identifying and aggressively pursing small molecules that increase global SUMOylation via the high throughput screening of compound libraries in an effort to advance neuroprotection and bring effective molecular therapies to bear.

\section{ACKNOWLEDGMENTS}

This research was supported by the Intramural Research Program of the NINDS/NIH. The authors wish to thank Dr. Dragan Maric (NINDS/NIH) for help with the FACS analysis.

\section{REFERENCES}

Abdullah, J. M., and Husin, A. (2011). Intravascular hypothermia for acute hemorrhagic stroke: a pilot study. Acta Neurochir. Suppl. 111, 421-424. doi: 10. 1007/978-3-7091-0693-8_72

Arsenijevic, D., de Bilbao, F., Plamondon, J., Paradis, E., Vallet, P., Richard, D., et al. (2006). Increased infarct size and lack of hyperphagic response after focal cerebral ischemia in peroxisome proliferator-activated receptor betadeficient mice. J. Cereb. Blood Flow Metab. 26, 433-445. doi: 10.1038/sj.jcbfm.96 00200

Broussalis, E., Killer, M., McCoy, M., Harrer, A., Trinka, E., and Kraus, J. (2012a). Current therapies in ischemic stroke. Part A. Recent developments in acute stroke treatment and in stroke prevention. Drug Discov. Today 17, 296-309. doi: 10.1016/j.drudis.2011.11.005

Broussalis, E., Trinka, E., Killer, M., Harrer, A., McCoy, M., and Kraus, J. (2012b). Current therapies in ischemic stroke. Part B. Future candidates in stroke therapy and experimental studies. Drug Discov. Today 17, 671-684. doi: 10.1016/j.drudis. 2012.02.011

Choi, K. E., Hall, C. L., Sun, J. M., Wei, L., Mohamad, O., Dix, T. A., et al. (2012). A novel stroke therapy of pharmacologically induced hypothermia after focal cerebral ischemia in mice. FASEB J. 26, 2799-2810. doi: 10.1096/fj.11201822

Cimarosti, H., Ashikaga, E., Jaafari, N., Dearden, L., Rubin, P., Wilkinson, K. A., et al. (2012). Enhanced SUMOylation and SENP-1 protein levels following oxygen and glucose deprivation in neurones. J. Cereb. Blood Flow Metab. 32, 17-22. doi: $10.1038 /$ jcbfm.2011.146

Cimarosti, H., Lindberg, C., Bomholt, S. F., Rønn, L. C., and Henley, J. M. (2008). Increased protein SUMOylation following focal cerebral ischemia. Neuropharmacology 54, 280-289. doi: 10.1016/j.neuropharm.2007.09.010

Datwyler, A. L., Lättig-Tünnemann, G., Yang, W., Paschen, W., Lee, S. L., Dirnagl, U., et al. (2011). SUMO2/3 conjugation is an endogenous neuroprotective mechanism. J. Cereb. Blood Flow Metab. 31, 2152-2159. doi: 10.1038/jcbfm. 2011.112

Dirnagl, U., Iadecola, C., and Moskowitz, M. A. (1999). Pathobiology of ischaemic stroke: an integrated view. Trends Neurosci. 22, 391-397. doi: 10.1016/s01662236(99)01401-0

Evdokimov, E., Sharma, P., Lockett, S. J., Lualdi, M., and Kuehn, M. R. (2008). Loss of SUMO1 in mice affects RanGAP1 localization and formation of PML nuclear bodies, but is not lethal as it can be compensated by SUMO2 or SUMO3. J. Cell Sci. 121, 4106-4113. doi: 10.1242/jcs.038570

González-Ibarra, F. P., Varon, J., and López-Meza, E. G. (2011). Therapeutic hypothermia: critical review of the molecular mechanisms of action. Front. Neurol. 2:4. doi: 10.3389/fneur.2011.00004

Hallenbeck, J. M. (2002). The many faces of tumor necrosis factor in stroke. Nat. Med. 8, 1363-1368. doi: 10.1038/nm1202-1363

Hallenbeck, J. M., and Frerichs, K. U. (1993). Stroke therapy. It may be time for an integrated approach. Arch. Neurol. 50, 768-770. doi: 10.1001/archneur.1993. 00540070080020

Hay, R. T. (2005). SUMO: a history of modification. Mol. Cell 18, 1-12. doi: 10. 1016/j.molcel.2005.03.012
Hayashi, T., Seki, M., Maeda, D., Wang, W., Kawabe, Y., Seki, T., et al. (2002). Ubc9 is essential for viability of higher eukaryotic cells. Exp. Cell Res. 280, 212-221. doi: 10.1006/excr.2002.5634

Iadecola, C., and Anrather, J. (2011). Stroke research at a crossroad: asking the brain for directions. Nat. Neurosci. 14, 1363-1368. doi: 10.1038/nn.2953

Katz, L. M., Young, A., Frank, J. E., Wang, Y., and Park, K. (2004). Neurotensininduced hypothermia improves neurologic outcome after hypoxic-ischemia. Crit. Care Med. 32, 806-810. doi: 10.1097/01.ccm.0000114998.00860.fd

Kollmar, R., Juettler, E., Huttner, H. B., Dörfler, A., Staykov, D., Kallmuenzer, B., et al. (2012). Cooling in intracerebral hemorrhage (CINCH) trial: protocol of a randomized German-Austrian clinical trial. Int. J. Stroke 7, 168-172. doi: 10. 1111/j.1747-4949.2011.00707.x

Krieger, D. W., and Yenari, M. A. (2004). Therapeutic hypothermia for acute ischemic stroke: what do laboratory studies teach us? Stroke 35, 1482-1489. doi: 10.1161/01.str.0000126118.44249.5c

Leach, M. J., Swan, J. H., Eisenthal, D., Dopson, M., and Nobbs, M. (1993). BW619C89, a glutamate release inhibitor, protects against focal cerebral ischemic damage. Stroke 24, 1063-1067. doi: 10.1161/01.str.24.7.1063

Lee, Y. J., Castri, P., Bembry, J., Maric, D., Auh, S., and Hallenbeck, J. M. (2009). SUMOylation participates in induction of ischemic tolerance. J. Neurochem. 109, 257-267. doi: 10.1111/j.1471-4159.2009.05957.x

Lee, Y. J., Miyake, S., Wakita, H., McMullen, D. C., Azuma, Y., Auh, S., et al. (2007). Protein SUMOylation is massively increased in hibernation torpor and is critical for the cytoprotection provided by ischemic preconditioning and hypothermia in SHSY5Y cells. J. Cereb. Blood Flow Metab. 27, 950-962. doi: 10.1038/sj.jcbfm. 9600395

Lee, Y. J., Mou, Y., Maric, D., Klimanis, D., Auh, S., and Hallenbeck, J. M. (2011). Elevated global SUMOylation in Ubc9 transgenic mice protects their brains against focal cerebral ischemic damage. PLoS One 6:e25852. doi: 10. 1371/journal.pone.0025852

Loftus, L. T., Gala, R., Yang, T., Jessick, V. J., Ashley, M. D., Ordonez, A. N., et al. (2009). Sumo-2/3-ylation following in vitro modeled ischemia is reduced in delayed ischemic tolerance. Brain Res. 1272, 71-80. doi: 10.1016/j.brainres.2009. 03.034

Macleod, M. R., Petersson, J., Norrving, B., Hacke, W., Dirnagl, U., Wagner, M., et al. (2010). Hypothermia for stroke: call to action 2010. Int. J. Stroke 5, 489492. doi: 10.1111/j.1747-4949.2010.00520.x

Mergenthaler, P., Dirnagl, U., and Meisel, A. (2004). Pathophysiology of stroke: lessons from animal models. Metab. Brain Dis. 19, 151-167. doi: 10. 1023/b:mebr.0000043966.46964.e6

Mou, Y., Wilgenburg, B. J., Lee, Y. J., and Hallenbeck, J. M. (2013). A method for hypothermia-induction and maintenance allows precise body and brain temperature control in mice. J. Neurosci. Methods 213, 1-5. doi: 10.1016/j. jneumeth.2012.11.006

Müller, S., Hoege, C., Pyrowolakis, G., and Jentsch, S. (2001). SUMO, ubiquitin's mysterious cousin. Nat. Rev. Mol. Cell Biol. 2, 202-210. doi: 10.1038/35056591

Nacerddine, K., Lehembre, F., Bhaumik, M., Artus, J., Cohen-Tannoudji, M., Babinet, C., et al. (2005). The SUMO pathway is essential for nuclear integrity and chromosome segregation in mice. Dev. Cell 9, 769-779. doi: 10.1016/j. devcel.2005.10.007

Nagel, S., Papadakis, M., Hoyte, L., and Buchan, A. M. (2008). Therapeutic hypothermia in experimental models of focal and global cerebral ischemia and intracerebral hemorrhage. Expert Rev. Neurother. 8, 1255-1268. doi: 10. 1586/14737175.8.8.1255

Nishio, S., Yunoki, M., Chen, Z. F., Anzivino, M. J., and Lee, K. S. (2000). Ischemic tolerance in the rat neocortex following hypothermic preconditioning. J. Neurosurg. 93, 845-851. doi: 10.3171/jns.2000.93.5.0845

O'Collins, V. E., Donnan, G. A., Macleod, M. R., and Howells, D. W. (2009). Scope of preclinical testing versus quality control within experiments. Stroke 40:e497. doi: 10.1161/STROKEAHA.109.550335

O’Collins, V. E., Macleod, M. R., Donnan, G. A., Horky, L. L., van der Worp, B. H., and Howells, D. W. (2006). 1,026 experimental treatments in acute stroke. Ann. Neurol. 59, 467-477. doi: 10.1002/ana.20741

Roger, V. L., Go, A. S., Lloyd-Jones, D. M., Benjamin, E. J., Berry, J. D., Borden, W. B., et al. (2012). Heart disease and stroke statistics-2012 update: a report from the American Heart Association. Circulation 125, e2-e220. doi: 10. 1161/CIR.0b013e31823ac046

Tatham, M. H., Jaffray, E., Vaughan, O. A., Desterro, J. M., Botting, C. H., Naismith, J. H., et al. (2001). Polymeric chains of SUMO-2 and SUMO-3 are conjugated 
to protein substrates by SAE1/SAE2 and Ubc9. J. Biol. Chem. 276, 35368-35374. doi: 10.1074/jbc.m104214200

Tempé, D., Piechaczyk, M., and Bossis, G. (2008). SUMO under stress. Biochem. Soc. Trans. 36, 874-878. doi: 10.1042/BST0360874

van der Worp, H. B., Macleod, M. R., Kollmar, R., and European Stroke Research Network for Hypothermia (EuroHYP). (2010). Therapeutic hypothermia for acute ischemic stroke: ready to start large randomized trials? J. Cereb. Blood Flow Metab. 30, 1079-1093. doi: 10.1038/jcbfm.2010.44

Wang, L., Ma, Q., Yang, W., Mackensen, G. B., and Paschen, W. (2012). Moderate hypothermia induces marked increase in levels and nuclear accumulation of SUMO2/3-conjugated proteins in neurons. J. Neurochem. 123, 349-359. doi: 10. $1111 / j .1471-4159.2012 .07916 . x$

Yang, W., Ma, Q., Mackensen, G. B., and Paschen, W. (2009). Deep hypothermia markedly activates the small ubiquitin-like modifier conjugation pathway; implications for the fate of cells exposed to transient deep hypothermic cardiopulmonary bypass. J. Cereb. Blood Flow Metab. 29, 886-890. doi: 10. $1038 / j \mathrm{jbfm} .2009 .16$

Yang, W., Sheng, H., Homi, H. M., Warner, D. S., and Paschen, W. (2008). Cerebral ischemia/stroke and small ubiquitin-like modifier (SUMO) conjugation-a new target for therapeutic intervention? J. Neurochem. 106, 989-999. doi: 10.1111/j. 1471-4159.2008.05404.x

Yenari, M. A., and Han, H. S. (2012). Neuroprotective mechanisms of hypothermia in brain ischaemia. Nat. Rev. Neurosci. 13, 267-278. doi: 10.1038/ nrn3174

Yenari, M., Kitagawa, K., Lyden, P., and Perez-Pinzon, M. (2008). Metabolic downregulation: a key to successful neuroprotection? Stroke 39, 2910-2917. doi: 10.1161/STROKEAHA.108.514471
Yunoki, M., Nishio, S., Ukita, N., Anzivino, M. J., and Lee, K. S. (2002). Characteristics of hypothermic preconditioning influencing the induction of delayed ischemic tolerance. J. Neurosurg. 97, 650-657. doi: 10.3171/jns.2002.97. 3.0650

Yunoki, M., Nishio, S., Ukita, N., Anzivino, M. J., and Lee, K. S. (2003). Hypothermic preconditioning induces rapid tolerance to focal ischemic injury in the rat. Exp. Neurol. 181, 291-300. doi: 10.1016/s0014-4886(03)00056-6

Zhang, F. P., Mikkonen, L., Toppari, J., Palvimo, J. J., Thesleff, I., and Jänne, O. A. (2008). Sumo-1 function is dispensable in normal mouse development. Mol. Cell. Biol. 28, 5381-5390. doi: 10.1128/MCB.00651-08

Conflict of Interest Statement: The authors declare that the research was conducted in the absence of any commercial or financial relationships that could be construed as a potential conflict of interest.

Received: 13 October 2014; accepted: 16 November 2014; published online: 04 December 2014.

Citation: Lee Y-j, Mou Y, Klimanis D, Bernstock JD and Hallenbeck JM (2014) Global SUMOylation is a molecular mechanism underlying hypothermia-induced ischemic tolerance. Front. Cell. Neurosci. 8:416. doi: 10.3389/fncel.2014.00416

This article was submitted to the journal Frontiers in Cellular Neuroscience.

Copyright (๑) 2014 Lee, Mou, Klimanis, Bernstock and Hallenbeck. This is an openaccess article distributed under the terms of the Creative Commons Attribution License (CC BY). The use, distribution and reproduction in other forums is permitted, provided the original author(s) or licensor are credited and that the original publication in this journal is cited, in accordance with accepted academic practice. No use, distribution or reproduction is permitted which does not comply with these terms. 